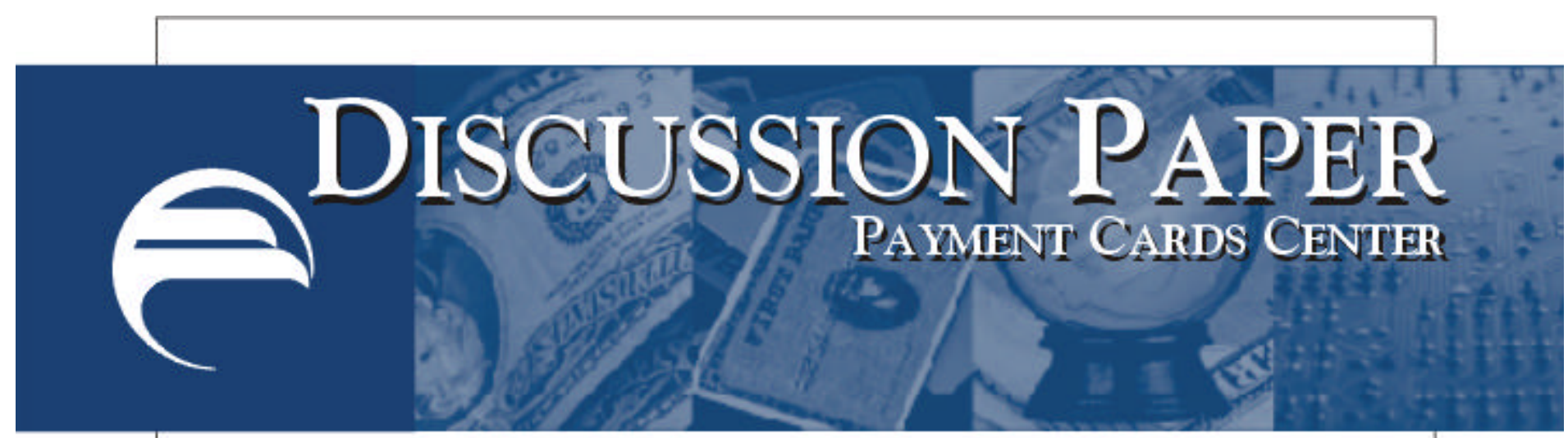

\title{
An Overview of Smart Card Technology and Markets*
}

\author{
Mark Furletti
}

April 2002

Summary: As part of the Payment Cards Center's series of discussion papers, this paper provides an overview of smart card technology and its potential for significantly increasing payment card functionality. In addition to reviewing the current market for smart cards in the US, this paper examines the costs and barriers associated with their wide spread adoption. European and US smart card acceptance is compared. In addition, this paper provides background on the technological and infrastructure developments behind smart cards, a discussion of current smart card applications, and a review of smart card adoption in banking.

*The views expressed here are not necessarily those of this Reserve Bank or of the Federal Reserve System.

\section{Federal Reserve Bank of Philadelphia}


Named for their ability to process information via an embedded computer chip, "smart cards" could become the most significant technological advance in payment cards since the introduction of the magnetic stripe on credit cards. While the credit card is the payment vehicle of choice for many consumers, its basic functionality has changed very little since the introduction of the branded bankcard in the 1950s. In contrast, possible applications of smart cards extend well beyond just making purchases. Smart cards have been widely used in banking, health care, and telecommunications applications across Europe since the 1980s. Today, they can be found in almost all European mobile phones, in many credit and banking cards, and in public transportation access cards. Unlike their magnetic stripe predecessors that store very small amounts of read-only data, smart cards have their own microprocessor. This microprocessor enables smart cards to not only store data but also update the data it stores, receive data, make decisions about data that it stores and receives, and detect unauthorized attempts to read its contents.

\section{The Market for Plastic Cards}

Last year 10 billion plastic cards (including magnetic stripe, nonmagnetic stripe, and smart cards) were produced worldwide. ${ }^{2}$ Approximately 2 billion of these were manufactured with an embedded chip and put to use in the following industries: ${ }^{3}$

- Telecommunications (78\%)

- $\quad$ Banking $(7 \%)$

- Health care (3\%)

- Transportation (2\%)

\footnotetext{
2 “Cards Manufactured Worldwide by Type,” The Nilson Report, Vol. 749: 6 (October 2001).
} 
- Other $(10 \%)$

The overwhelming majority of smart cards produced last year, over 1.6 billion, were used in telecommunication applications. This was driven by the use of smart cards as payment cards for European public telephones and as subscriber information modules (SIMs) in mobile phones that use GSM (global system for mobile communications) technology — a popular standard in Europe. Every GSM mobile phone accepts a smart card. Referred to as a SIM, this smart card is not necessarily the same size as a credit card. ${ }^{4}$ It can be used to store a consumer's phone number, address book, and phone service information. If a consumer's phone breaks or is upgraded, the smart card can be removed from the old phone and placed in the new one - all while retaining the customer's previously stored information.

\section{Smart Card Manufacturing}

The smart card manufacturing industry is highly concentrated, with three companies producing almost three-quarters of all smart cards last year: Gemplus (623 million), SchlumbergerSema (555 million), and Giesecke \& Devrient (216 million). ${ }^{5}$ The smart cards that these and other manufacturers produce are of two basic varieties: those that require contact with a reader to be accessed (contact smart cards) and those that do not (contactless smart cards). With the exception of a small antenna embedded in the contactless card, the basic design of the two is the same. Both have an integrated circuit embedded in a credit card-sized piece of plastic. The contact card, however, has a small gold plate about one-half inch in diameter that covers the circuit. This plate is used to make

\footnotetext{
3 "Smart Card Growth," Cartes 2002. <http://www.cartesexpo.com>.

4 "4.3 Telecommunications," Australasian Legal Information Institute. <http: //www.austlii.edu.au/au/other/ privacy/smart/43.html $>$.

5 “Top Chip Manufacturers Worldwide,” The Nilson Report, Vol. 749: 6 (October 2001).
} 
contact with the electrical connectors inside a credit-card-like reader and allows data to be sent to and from the chip.

Since contactless cards can communicate with an antenna or coupler unit without being inserted into a reader, they are ideal for transactions that must be processed very quickly, such as mass-transit or toll collection activities. In 2001, approximately one-third of the smart cards produced worldwide were contactless. ${ }^{6}$

Smart card integrated circuits, or chips, are manufactured from silicon wafers just like other computer chips. These circuits are bonded to aluminum contact areas (to ensure readability) and encapsulated in an epoxy resin before being embedded in plastic cards. The card portion of smart cards, like magnetic stripe cards, is manufactured from sheets of plastic, except smart cards have a small channel milled in the card deep enough to fit the encapsulated chip. The computer chip, having been embedded in the card, is tested to ensure that the resulting card functions properly.

\section{The Smart Card's Computer Chip}

Since smart cards have a central processing unit (CPU), an operating system, and different types of memory contained on their computer chip, their anatomy is very much like that of a personal computer's. Smart cards depend on power supplied to them either directly from an electrical connector inside a card reader or indirectly from the radio frequency transmissions of contactless readers. The main functional elements of the chip include:

\section{- Central Processing Unit (CPU)}

The chip's central processing unit interprets and executes instructions delivered to it by the operating system. 


\section{- Read-Only Memory (ROM)}

The read-only memory stores data that, once written, cannot be changed or removed. For this reason, chipmakers store the card's operating system as well as various testing and diagnostic functions in the ROM portion of the chip. ROM's content does not depend on power.

- Random-Access Memory (RAM)

The random access memory acts as the central processing unit's "scratchpad." It can store and modify data written to it during a session of use and be accessed as many times as necessary as long as it is supplied power. When it stops receiving power, its contents are permanently lost.

\section{- Application Memory (EEPROM)}

For data that need to be modified or erased, like application data, chipmakers use electrically erasable programmable read-only memory (EEPROM). EEPROM is very similar to a personal computer's hard disk, since the data stored on it can remain in the memory in the absence of power and be continuously modified during a session. In smart cards produced thus far, this memory is eight or 16 kilobytes. In contrast, a magnetic stripe card has only 0.14 kilobytes of memory.

\section{Recent Smart Card Developments in the U.S.}

Although over 80 percent of smart cards produced last year were earmarked for telecommunication applications in Europe, smart cards are making in-roads in the U.S., particularly in the retail, government, and financial sectors. Some organizations are finding smart cards to be an efficient way to manage and access benefits, money, physical spaces,

\footnotetext{
${ }^{6}$ “Top Chip Manufacturers Worldwide,” The Nilson Report, Vol. 749: 6 (October 2001).
} 
and rewards. Some examples of smart cards being adopted by U.S. organizations for loyalty, identification, credit card, and benefit program applications include:

\section{- Target Corporation}

In an effort to capitalize on the loyalty of its customer base and improve its ability to market to its customers, the Minneapolis-based retailer launched a smart credit card program in September of last year. In just a few months it signed up more than 2 million of its shoppers for a Visa smart card. These Target-card-carrying customers will be able to use their Gemplus-manufactured smart cards in any of the 40,000 readers installed at 1,000 Target stores. Leveraging the chip technology, Target has plans for extending special offers, coupons, and loyalty programs to customers with Target-branded smart cards.

\section{- The Department of Defense}

Leveraging the identification and access functionality inherent in smart cards, the U.S. Department of Defense (DoD) plans to issue 4.3 million smart cards to its military and civilian employees. ${ }^{7}$ These smart cards, produced by SchlumbergerSema, will be used for physical identification and to grant building and network access to employees at over 900 DoD sites. The smart cards used by the DoD will incorporate digital signature technology and provide a highly portable and secure method of granting network access and communicating electronically.

\section{- Providian, Fleet, and First USA}

These three Visa issuers have begun marketing credit cards with a magnetic stripe and a chip, despite the chip's initial lack of any real functionality. Since merchants are not equipped with smart card readers, these issuers have initially targeted tech-savvy 
consumers with marketing messages that promote the card's unique look and its limited Internet shopping functionality. Somewhat surprisingly, mailings that tout smart cards have received higher response rates than those offering traditional magnetic stripe cards. As the chip's functionality expands to include reward programs, loyalty programs, and other enhanced applications, issuers will likely target smart cards to a broader audience.

\section{- The State of Ohio}

Leveraging the capability of the smart card chip to track an individual's use of government benefits, Ohio issued 300,000 smart cards to residents who qualified for its state-sponsored meal program. ${ }^{8}$ The smart card enables beneficiaries to receive select products such as milk for free and to get discounts on other food products.

\section{Smart Cards \& Banking}

In 2001, Europeans were using 84 percent of the 233 million bank-application smart cards in the world, while just 5 percent, or 12 million, were being used by consumers in the U.S. ${ }^{9}$ Driven by savings in telecommunications and fraud costs, the banking industry in Europe has embraced smart card over magnetic stripe technology. Since a smart card can authorize purchases based on data stored on its chip, each purchase does not require a phone call to a card issuer's remote authorization system. Given that telecommunication costs are higher in Europe than in the U.S., issuers have realized telecommunications savings by not having to authorize each purchase by phone.

\footnotetext{
7 "Chip Cards Break Out of Their Shell," Credit Card Management (January 25, 2002).

8 "Smart Card Systems: Ohio Direction Card and Paywest," Welfare Information Network. $<$ http://www.welfareinfo.org/smartcardsystem.htm>

9 "Smart Cards in US Banking: Is the Chip Hip?" Celent Communications

$<$ http://www.celent.com/pressreleases/20011018/smartcard.htm> (October 18, 2001).
} 
In addition, Europeans' use of personal identification numbers (PINs) verified by the smart card at the point of sale has significantly lowered fraud costs. Unlike debit cards that transmit a PIN over a network for verification, smart banking cards can verify a PIN without the number ever leaving the confines of the smart card reader, thus precluding the need for authentication via phone lines. In the U.S., where it is estimated that fraud costs are 7 basis points ( 0.07 percent) of the dollar value of purchase volume, the low relative cost of fraud has not been enough by itself to encourage widespread adoption of smart cards. ${ }^{10}$ At the same time, some observers believe that the relatively high level of payment fraud on the Internet might soon prove an attractive application for smart card authentication.

In Europe, two of the three key credit card constituencies, issuers and merchants, have benefited from the adoption of smart card technology. Credit card issuers, because of the significantly lower fraud and telecommunications costs associated with smart cards, have profited from the chip card's expanded use. These profits were sufficient to induce issuers to offer the second constituency, merchants, incentives for accepting smart cards. By reducing the per transaction fees that merchants were required to pay issuers each time a smart card was used, merchants were willing to accept smart cards. For the third constituency, the consumer, however, European smart cards essentially offer the same functionality as a standard magnetic stripe card and have been slow to provide any additional applications that would provide enhanced benefits to consumers.

The telecommunications and fraud environment in the U.S., however, is quite different, and benefits like those that motivated European issuers and merchants have not

\footnotetext{
10 "Visa Wants Merchants to Accept Smart Cards at the Point of Sale," Card Technology, $<$ http://www.cardtechnology.com> (May 11, 2001).
} 
yet manifested themselves. Obstacles to widespread deployment in the U.S. payments sector include merchants' reluctance to buy expensive chip-card-reading terminals, the inability of issuers to find chip card applications that increase the overall profitability of its customer relationships, and the lack of compelling applications that cause consumers to demand chip cards.

\section{The Costs of Smart Credit Cards}

Magnetic stripe credit cards cost credit card issuers about $\$ 0.50$ each, while singleapplication smart cards offering the exact same functionality as a magnetic stripe card cost about $\$ 0.99$ each. Smart cards that can run multiple applications (e.g., having credit card functionality and managing a rewards program) store 16 kilobytes of data but cost almost four times as much as magnetic stripe cards $-\$ 2.89$ each. ${ }^{11}$

According to Card Technology magazine, between 15 and 20 million magnetic stripe card readers are deployed in the U.S. It is estimated that the cost of replacing or upgrading all of these readers and replacing all of the country's magnetic stripe plastics would be $\$ 7$ billion to $\$ 10$ billion.

Further complicating the cost of a national migration to smart cards is the issue of interchange. Interchange, a transaction fee that the merchants' banks pay to credit card issuers, represents a key source of revenue for issuers. Since the use of smart cards could drive down the costs that interchange is intended to cover, some industry experts believe that increased use of smart cards could lead to decreased interchange revenues for credit card issuers. This confusion over network impact may also contribute to slower adoption by issuers in the absence of other revenue sources for smart cards' use. 


\section{The Future of Smart Credit Cards in the U.S.}

Because the potential for reducing fraud- and telecommunication-costs has not yet persuaded U.S. card issuers, smart card proponents and trade groups are searching for other benefits to spur their adoption. The challenge is to persuade some, if not all, of the three key constituencies in the payment card market (e.g., those who issue the cards, those who use the cards, and those who accept the cards) that the chip provides value-added functionality sufficient to justify its higher cost relative to magnetic stripe cards. To encourage acceptance, proponents of smart cards (e.g., The Smart Card Alliance) point to the ability of chip cards to store multiple applications. A single computer chip on a single plastic card, they say, could remember consumers' passwords, ensure secure online shopping, store coupons and loyalty program information, and reduce the costs merchants pay for fraudulent card use. The key question is, are these benefits enough to induce adoption?

Outside of the few credit card issuers, smart cards for financial service applications have not yet taken hold in the U.S. It is estimated that there are just 17.5 million chipbased cards in circulation, including those issued by bank and non-bank financial institutions. ${ }^{12}$ Recent mainstream media attention has been lukewarm. Saul Hansell's article published last fall in the New York Times, "Credit Card Chips with Little to Do," captured smart card critics' sentiments by asserting, "The cards may be smart, but so far they have not shown it." He argues, essentially, that issuers have not yet developed a compelling value proposition for smart cards' widespread use.

\footnotetext{
11 "The Coming of the \$0.99 Smart Card," Card Technology 6 (September 2001).
} 


\section{Conclusion}

Smart card technology, with its ability to verify identification and store and update information, is likely to help solve problems well beyond those of the financial services industry. From a payment system perspective, however, smart cards will have to overcome several barriers unrelated to technology before they gain widespread acceptance.

These barriers include higher product costs, higher card-reader costs, uncertain network impacts, and a perception that a smart card is simply a high-tech solution in search of a problem. If these are overcome, as proponents hope, smart cards could enable card issuers to precisely market loyalty-related products and services to its customers while protecting them from unauthorized card usage.

\footnotetext{
${ }^{12}$ Lavonne Kuykendall, "TowerGroup Offers Rosy Forecast for Chips in U.S," American Banker 9 (January 29, 2002).
} 